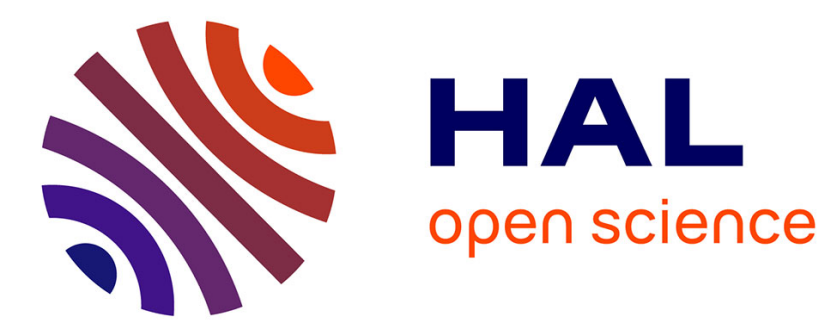

\title{
The microstructural properties of sputtered zinc oxide SAW transducers
}

\author{
F.S. Hickernell
}

\section{To cite this version:}

F.S. Hickernell. The microstructural properties of sputtered zinc oxide SAW transducers. Revue de Physique Appliquée, 1985, 20 (6), pp.319-324. 10.1051/rphysap:01985002006031900 . jpa-00245339

\section{HAL Id: jpa-00245339 https://hal.science/jpa-00245339}

Submitted on 1 Jan 1985

HAL is a multi-disciplinary open access archive for the deposit and dissemination of scientific research documents, whether they are published or not. The documents may come from teaching and research institutions in France or abroad, or from public or private research centers.
L'archive ouverte pluridisciplinaire HAL, est destinée au dépôt et à la diffusion de documents scientifiques de niveau recherche, publiés ou non, émanant des établissements d'enseignement et de recherche français ou étrangers, des laboratoires publics ou privés. 


\title{
The microstructural properties of sputtered zinc oxide SAW transducers
}

\author{
F. S. Hickernell \\ Motorola Inc., Government Electronics Group, Scottsdale, Arizona 85252, U.S.A.
}

(Reçu le 7 septembre 1984, accepté le 9 novembre 1984)

\begin{abstract}
Résumé. - Les propriétés microstructurales de l'oxyde de zinc pulvérisé sont étudiées et reliées à leur aptitude à la transduction piézoélectrique pour ondes de surface. Les films transducteurs à onde de surface sont déposés sur des supports en verre en faisant varier les conditions du dépôt de façon à atteindre différents degrés d'efficacité de transduction. La microstructure du film de $\mathrm{ZnO}$ est analysée par diffraction $\mathrm{X}$, profilométrie de surface et microscopie électronique à balayage. Des techniques de gravure sont également employées pour préciser les propriétés microstructurales.

Les films à bas facteur de couplage sont mal cristallisés; ils ont une topographie de surface plus rugueuse et des taux élevés de gravure.

Les films à haut facteur de couplage sont bien ordonnés, denses structuralement; ils ont des surfaces lisses et des figures de gravure caractéristiques des monocristaux d'oxyde de zinc.

Les différences proviennent des conditions de croissance qui produisent une structure de film à basse densité de défauts, une polarité uniforme avec un minimum d'inversion de grain et des joints de grain peu marqués.

Abstract. - The microstructural properties of sputtered zinc oxide, $\mathrm{ZnO}$, were investigated and related to their effective surface acoustic wave, SAW, transducer capabilities. SAW transducer films were fabricated on glass using different deposition parameters to produce different levels of transducer efficiency. The $\mathrm{ZnO}$ film microstructure was analysed using X-ray diffraction, surface profilometer and scanning electron microscope equipment. Etch techniques were used to further delineate the microstructural properties. The low coupling factor films had a low crystalline content, rougher surface topography and high etch rates. High coupling factor films were highly ordered, structurally dense, smooth surfaced films with etch properties characteristic of single crystal zinc oxide. The differences relate to growth conditions which produce a low defect density film structure of uniform polarity with a minimum of fibre grain inversions and weak intergrain boundaries.
\end{abstract}

\section{Introduction.}

Zinc oxide thin-film transducers are used in a variety of microwave acoustic device applications for the generation and detection of acoustic waves. The films are normally sputter deposited with electrode configurations which produce an efficient transformation from rf energy to elastic motion within a particular frequency band. This transformation is via the piezoelectric effect which is relatively strong for such a simple nonferroelectric metal oxide compound. The piezoelectric property of sputtered zinc oxide films can approach that of the single crystal material.

Various aspects of thin-film $\mathrm{ZnO}$ process technology have been summarized in a previous publication [1]. It is the purpose of this paper to consider the relationship between the microstructural properties of sputtered zinc oxide and its piezoelectric properties as evidenced by transducer conversion efficiency. The discussion will be limited to surface acoustic wave (SAW) transducer structures in the upper VHF region. Various measures of film microstructural properties such as crystallinity, surface topography, chemical etch properties and defect density will be discussed. The main instrumentation for measuring the microstructural properties are X-ray diffraction (XRD), scanning electron microscope (SEM) and surface profilometer equipment. The piezoelectric quality of the $\mathrm{ZnO}$ films is determined by insertion loss measurements between arrayed SAW transducer structures.

There are electrical factors which can also affect the transducer coupling efficiency particularly if the film is a lossy dielectric or is in proximity to semiconducting substrates. Since the zinc oxide films described are of high resistivity and grown on insulating glass substrates these are not contributing factors.

The paper is divided into three major parts. First there is a brief discussion of the major factors which 
control the coupling efficiency of surface wave transducers. Second, measurement techniques and past experimental results which have related coupling efficiency to growth processes and microstructure are described. The third part of the paper describes the results of recent measurements on the structural parameters of dc triode sputtered $\mathrm{ZnO}$ SAW transducers and their relationship to the SAW transducer coupling factor, $k^{2}$.

The general conclusion reached from this investigation is that zinc oxide films which exhibit strong piezoelectric action for surface acoustic wave generation have microstructural characteristics which are directly relatable to the single crystal material. Such films have highly ordered, structurally dense crystalline content with etch properties characteristic of single crystal $\mathrm{ZnO}$.

\section{Background.}

Wagers and Kino [2] have analysed the relationship between the coupling efficiency of a film layer SAW transducer and the constituent contributions of its piezoelectric coupling terms. For a $C$-axis normal zinc oxide film on a nonpiezoelectric substrate there are contributions from longitudinal, shear and dilatational terms. For a film thickness near a half of an acoustic wavelength, where the theoretical coupling efficiency reaches its maximum value, the longitudinal $d_{33}$ and the shear $d_{15}$ terms dominate. The $d_{33}$ term produces a strain in the $C$-axis direction from the electric field component in the $C$-direction. The $d_{15}$ term produces a transverse shearing motion with polarization in the plane of the shear from the electric field component normal to the $C$-axis. It is these two terms which are given major consideration in analysing the relationship of film microstructure to transducer coupling efficiency.

The microstructure of a theoretically perfect film will have a dense fine grain fiber structure of aligned crystallites of the same polarity approximating a single crystal structure. If the fiber grains are crystallographically well oriented but do not have good boundary interconnections, the longitudinal $d_{33}$ coupling factor will predominate and the $d_{15}$ shear motion contribution will be dampened. For strong longitudinal coupling and weak shear coupling the overall transducer coupling factor will be reduced by a factor of 4 to 5. Also surface acoustic wave propagation losses will be high since the shear motion contributes over $70 \%$ to the total loss.

A second consideration is the ratio of well aligned crystallite structures to misaligned or amorphous like structures. Zinc oxide films have a strong tendency for the $C$-axis to be aligned normal to the substrate. A strong misalignment from the $C$-axis normal position will affect both the longitudinal and shear piezoelectric terms. The SAW transducer coupling factor, $k^{2}$, is reduced to one-half its value by an average alignment of the $C$-axis 45 degrees from normal. In practice, however, there is more apt to be a random variation in crystallite orientation than a fixed angular relationship of all the crystallites.

There has been considerable conjecture regarding polarity inversions of the $\mathrm{ZnO}$ fibre grains due to different nucleation conditions. Dybwad [3] has noted that different substrates can cause the oxygen or zinc face to be predominant at the substrate boundary. The presence of an oriented metal film will also affect the growth conditions and polarity of the zinc oxide fibre grains. Thus it is possible to have different polarization conditions in the transducer electrode region where metallized and unmetallized regions occur. If for example only $20 \%$ of the crystallites were polarity inverted the $k^{2}$ coupling factor would be reduced to $36 \%$ of its maximum value.

The aforementioned microstructural conditions can operate individually or collectively to reduce the transducer coupling factor of the film. Which factor predominates cannot easily be determined. However by considering structurally related analysis techniques some fairly strong arguments can be made regarding which mechanisms may predominate.

\section{Measurement considerations.}

Because crystalline ordering and structural integrity have been identified as major factors in piezoelectric coupling efficiency it is important to use techniques which delineate these features. For this purpose X-ray diffraction, chemical etching and SEM examination of surface features were chosen as the main analytical tools for relating microstructure to SAW transducer coupling efficiency.

$\mathrm{X}$-ray diffraction characterizes the crystallographic ordering of the zinc oxide films. Because the film grows with its $C$-axis normal to the substrate, a strong (002) peak is present in a well ordered film. Correlations are commonly made between the characteristics of the (002) diffraction peak, sputter process conditions and coupling factor. It has been found that crystallographic ordering is a necessary but not sufficient condition to assure high coupling efficiency. A high coupling factor film will always show a strong $C$-axis normal orientation. However, such a strong (002) diffraction peak may not result in a coupling efficiency near theoretical. For example an order of magnitude increase in the intensity of the (002) peak may show little increase in coupling factor as evidenced by the work of Schoenwald and coworkers [4].

Other information potentially obtained from the $\mathrm{X}$-ray diffractometer scan is the average strain level in the film and an indication of crystallite size. The displacement of the (002) diffraction peak from its normal powder value and the broadening of its width is primarily associated with nonlinear intrinsic stresses within the film. It has been experimentally observed that relieving this stress by post deposition annealing 
at moderate temperatures $\left(\sim 400^{\circ} \mathrm{C}\right)$ maintains the total integrated X-ray counts over the diffraction peak. Thus a better measure of the crystallographic ordering of the film is the total X-ray counts rather than the intensity of the peak value alone. Dividing this total integrated count by the film thickness gives a normalization which allows films of different thicknesses to be compared.

The surface topography of sputtered zinc oxide films has varied from nodular grain tops with surface roughness averaging near $0.5 \mu \mathrm{m}$ to smooth surfaces with roughness less than a few hundred angstroms. From the experimental evidence available the rougher columnar $\mathrm{ZnO}$ film structures are associated with the parameters of low substrate temperature, high gas pressure and low deposition rates. High substrate temperatures, low gas pressures and high deposition rates produce the much smoother surface textures. These latter deposition conditions are also consistent with the formation of a film with high crystalline ordering. The presence of a smooth surface implies a uniform growth rate of the film and its attendant lattice structure. A rough surface texture implies non uniform or selective growth in which certain regions grow more rapidly to the exclusion of others. This would induce structural flaws which would not support the induced elastic motions via the piezoelectric effect.

The surface roughness of a $\mathrm{ZnO}$ film can be accurately measured using a surface profilometer. With care roughness values down to $10 \AA$ to $20 \AA$ can be measured. The scanning electron microscope can aid in the determination of the general characteristics of the surface structure.

One of the earliest investigations of the correlation between SAW transducer coupling factor and microstructure was done by Bahr and Lee of SRI with $\mathrm{ZnO}$ samples provided from three independent sources [6]. Fracture sections were examined using the SEM to delineate the surface and sidewall texture of the $\mathrm{ZnO}$ films. There was a definite qualitative correlation between the fibre grain structure and coupling efficiency. Films with large grains and poor intergrain connecting structure (e.g., voids or mechanically weak boundaries) had very poor or zero coupling factor. Films with smooth surface features that were dense and did not show grain-like striations had high transducer coupling efficiencies.

The weakness of the intergrain structure could be more easily discerned under the SEM after chemically etching the side of fracture sections. The weak fibre grain structure films showed a rapid uneven etch with distinct remnant columnar structures. The dense $\mathrm{ZnO}$ films etched evenly preserving a smooth wall-like structure.

Zinc oxide readily etches in acid solutions. The etch rate of a $\mathrm{ZnO}$ crystal is highly anisotropic depending upon the crystallographic surface being etched. This has been noted by Mariano and Hanneman [5]. To provide a basis for comparison of film and crystal properties, etch rates along and normal to the $C$-axis of vapour phase grown $\mathrm{ZnO}$ crystals were determined. A $25 \%$ nitric acid solution was used. Along the $C$-axis the etch rate at the zinc surface was $32 \AA / s$ and at the oxygen surface it was $330 \AA / \mathrm{s}$. The etch rate normal to the surface was $1520 \AA$. Thus there is a 10:1 etch rate difference depending upon the $C$-axis surface being etched. If the etching is normal to the $C$-axis the rate is almost 50 times that of the zinc surface. This presents some very interesting possibilities for correlating film microstructure with coupling factor since the crystallographic and polarity properties of the films might be determined through SEM examination.

\section{Experimental.}

A series of $\mathrm{ZnO}$ films were dc triode sputtered on glass substrates patterned with a linear array of SAW transducer electrodes. Each aluminum transducer electrode had twenty quarter wavelength finger pairs with a wavelength periodicity of $12.2 \mu \mathrm{m}$. The patterns were spaced approximately $2.5 \mathrm{~mm}$ apart. The films ranged in thickness from $3.0 \mu \mathrm{m}$ to $6.0 \mu \mathrm{m}$. The substrate temperature, and deposition rate were varied to produce a group of films whose measured SAW coupling factors extended from $10 \%$ to $90 \%$ of theoretical. The microstructure of those films were examined by X-ray diffraction, surface profilometer, chemical etching and scanning electron microscopy using the equipment and techniques previously discussed.

The correspondence between coupling factor and process parameters which has been reported previously was observed with this investigation [7]. The lowest coupling factor films $(10-20 \%$ of theoretical) corresponded to water-cooled or unheated substrate conditions together with low deposition rates $(<2 \AA / s)$. The highest coupling factor films $(70-90 \%$ of theoretical) were grown on substrates with temperatures above $150^{\circ} \mathrm{C}$ and average rates greater than $3 \AA / \mathrm{s}$.

Table I. - The level of SAW transducer coupling efficiency related to the thickness normalized integrated $\mathrm{X}$-ray counts of the (002) peak.

\begin{tabular}{|c|c|}
\hline $\begin{array}{c}\text { Coupling factor } \\
(\% \text { of theoretical })\end{array}$ & $\begin{array}{c}\text { Normalized X-ray counts } \\
(\mathrm{cps} / \AA)\end{array}$ \\
\hline$<25 \%$ & $<0.3$ \\
$25-50 \%$ & $0.2-0.5$ \\
$50-75 \%$ & $0.4-0.7$ \\
$>75 \%$ & $0.6->1.0$ \\
\hline
\end{tabular}

A relationship between transducer coupling factor and X-ray intensity that was observed is shown in table I. The transducer coupling factor is represented by its percentage of the calculated theoretical value 
for the particular thickness to wavelength ratio. The thickness to wavelength ratios span the range of 0.2 to 0.5 representative of theoretical $k^{2}$ coupling factor values from 0.01 to 0.03 . The measure of crystallographic ordering in the film is the integrated X-ray intensity across the (002) peak, divided by the film thickness. The results have been divided into quartiles by the strength of the coupling factor. Transducer coupling factors which are $25 \%$ or less of theoretical have X-ray intensity factors less than $0.3 \mathrm{cps} / \AA$. Those between $25 \%$ and $50 \%$ were in the range $0.2 \mathrm{cps} / \AA$ to $0.5 \mathrm{cps} / \AA$ and $50 \%$ to $75 \%$ range was 0.4 to $0.7 \mathrm{cps} / \AA$. The high coupling factor transducers greater than $75 \%$ of theoretical were above $0.6 \mathrm{cps} / \AA$ and extended as high as $5.0 \mathrm{cps} / \AA$. The change in the coupling factor is fairly rapid with improving crystallinity. On the average, one order of magnitude change in the X-ray intensity can increase the coupling efficiency from $10 \%$ of theoretical to $90 \%$ of theoretical. Thus as anticipated good structural ordering is consistent with a high coupling factor.

The relationship of the surface roughness of the $\mathrm{ZnO}$ films to coupling factor was not as definitive as the case for the X-ray diffraction. For a peak to valley surface roughness of $300 \AA$ or less the coupling factor was greater than $50 \%$ of theoretical. For a surface roughness of greater than $500 \AA$ the coupling factor was less than $50 \%$. The maximum surface roughness factor observed in the films was $1000 \AA$.

The surface topography was different under the various deposition conditions. For the low temperature substrates the surface consisted of broad uplifted mesa regions which were 40 to $60 \mu \mathrm{m}$ in extent with an average peak to valley difference level of 600 to $800 \AA$. The average distance between adjacent edges of the mesa regions was 20 to $40 \mu \mathrm{m}$. The high temperature, higher rate growth films with the smoother surface texture had a periodic surface roughness with an average period of 10 to $12 \mu \mathrm{m}$.

The etch rate of the films over the glass regions away from the electrodes varied from $200 \AA / \mathrm{s}$ to $1200 \AA / s$ with a 25:75 nitric acid to water ratio. The etch rate in the aluminum pad region was slower by up to a factor of 2. There was a correlation between coupling factor and the observed etch rate. For etch rates below $400 \AA / \mathrm{s}$ the coupling efficiency was greater than $75 \%$ of theoretical. Above $900 \AA / \mathrm{s}$ the coupling efficiency was less than $25 \%$ of theoretical.

In general, the slower etch rate films also had lower acoustic propagation losses. In a separate investigation it was determined that propagation losses at $200 \mathrm{MHz}$ were less than $10 \mathrm{~dB} / \mathrm{cm}$ for etch rates less than $400 \AA / \mathrm{s}$ and greater than $20 \mathrm{~dB} / \mathrm{cm}$ for etch rates over $900 \AA / s$.

The etch rate data supports the premise that higher coupling factor films with low acoustic propagation losses must have a stronger interconnected fibre grain structure to support the required shear motions. A rapid etch rate implies a much weaker fibre grain structure which is less resistant to the chemical etch process. The characteristics of the etch process are more clearly delineated by viewing the partially etched surfaces through SEM photographs.

Figure 1 shows the surface of a high coupling factor film before and after a short nitric acid etch. The 25:75 $\mathrm{HNO}_{3}: \mathrm{H}_{2} \mathrm{O}$ solution etch was followed by a vapor etch using the same concentration. It is obvious from figure $1 \mathrm{~b}$ that only selected sites have been attacked by the acid forming conical etch pits. Within the etch pits some additional fiber-like structure is observed. A defect density may be calculated and for this film it is in the range from 0.05 to 0.10 defects per square micrometer.

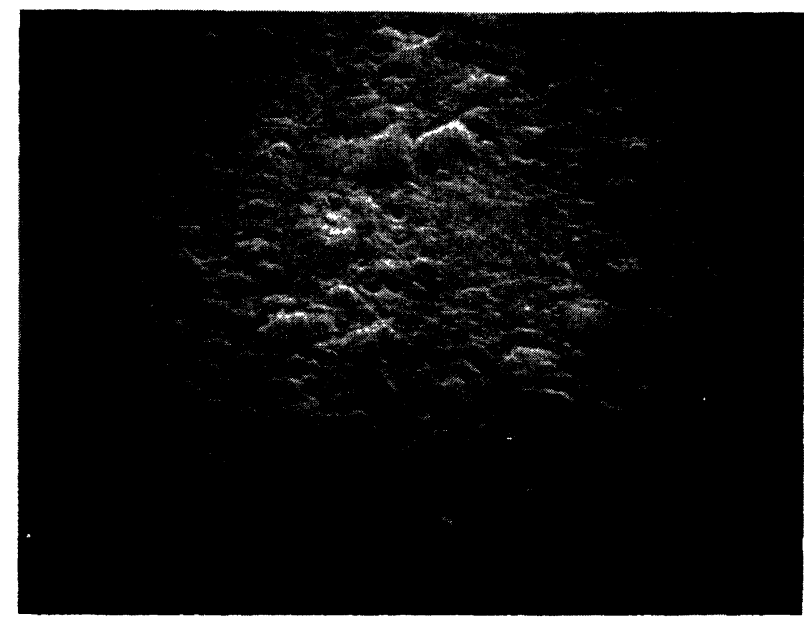

a)

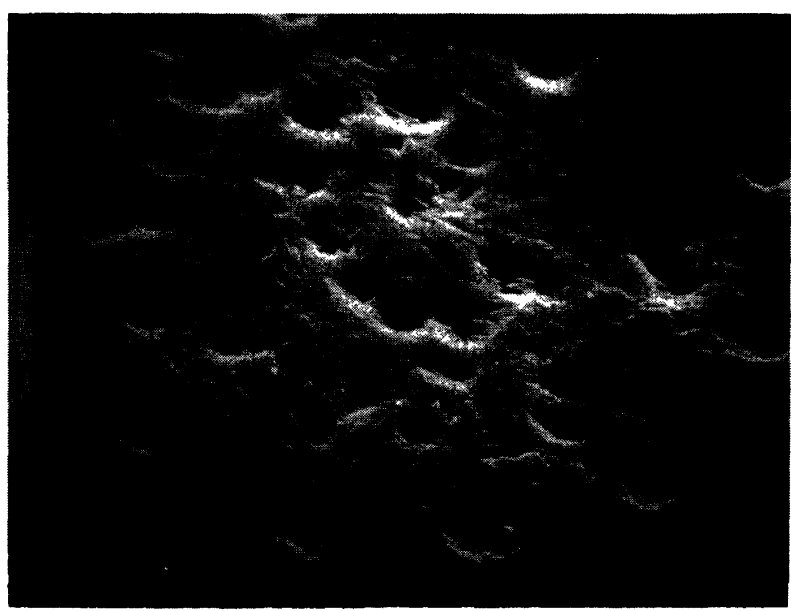

b)

Fig. 1. - The unetched a) and etched b) surface of a high coupling factor dc triode sputtered zinc oxide film.

The average diameter of the etch pits is $2 \mu \mathrm{m}$. The depth of the etch pits can be calculated from the SEM data assuming a uniform conical structure. The half cone angle is approximately $70^{\circ}$ leading to a depth of $0.36 \mu \mathrm{m}$. Such a shallow conical structure indicates an etch rate in the vertical that is about 3 times slower than that in the plane of the film. 
From the observed overall etch rate which was $400 \AA / \mathrm{s}$ for this $4.3 \mu \mathrm{m}$ film, vertical and lateral rates can be determined. The calculation yields a vertical etch rate of approximately $430 \AA / \mathrm{s}$ and a lateral rate of $1200 \AA / \mathrm{s}$. It is recalled that these rates are close to those determined for single crystal zinc oxide for etching along the $C$-axis oxygen surface and normal to the $C$-axis. Since the surface between the etch pits does not show signs of etching it could be implied that this is the zinc face of the film. Thus the defect areas may well represent fibre grain inversions in which the oxygen face is at the surface.

The low coupling factor material exhibits a much more random crystallographic structure as can be seen in figure 2. There are amorphous looking etch resistant hillock areas between randomly oriented crystallographic fibre like structural areas. For this film the overall etch rate was $900 \AA / \mathrm{s}$. The hillock areas may represent zinc face fibre grain regions which occupy a much smaller area than those in higher coupling factor materials. The ratio of hillocks to fiber structure is approximately one. If these were in fact polarity reversed structures a low coupling factor would be expected. The structure is obviously more loosely bound and randomly oriented in its structural properties than that of figure 1 .
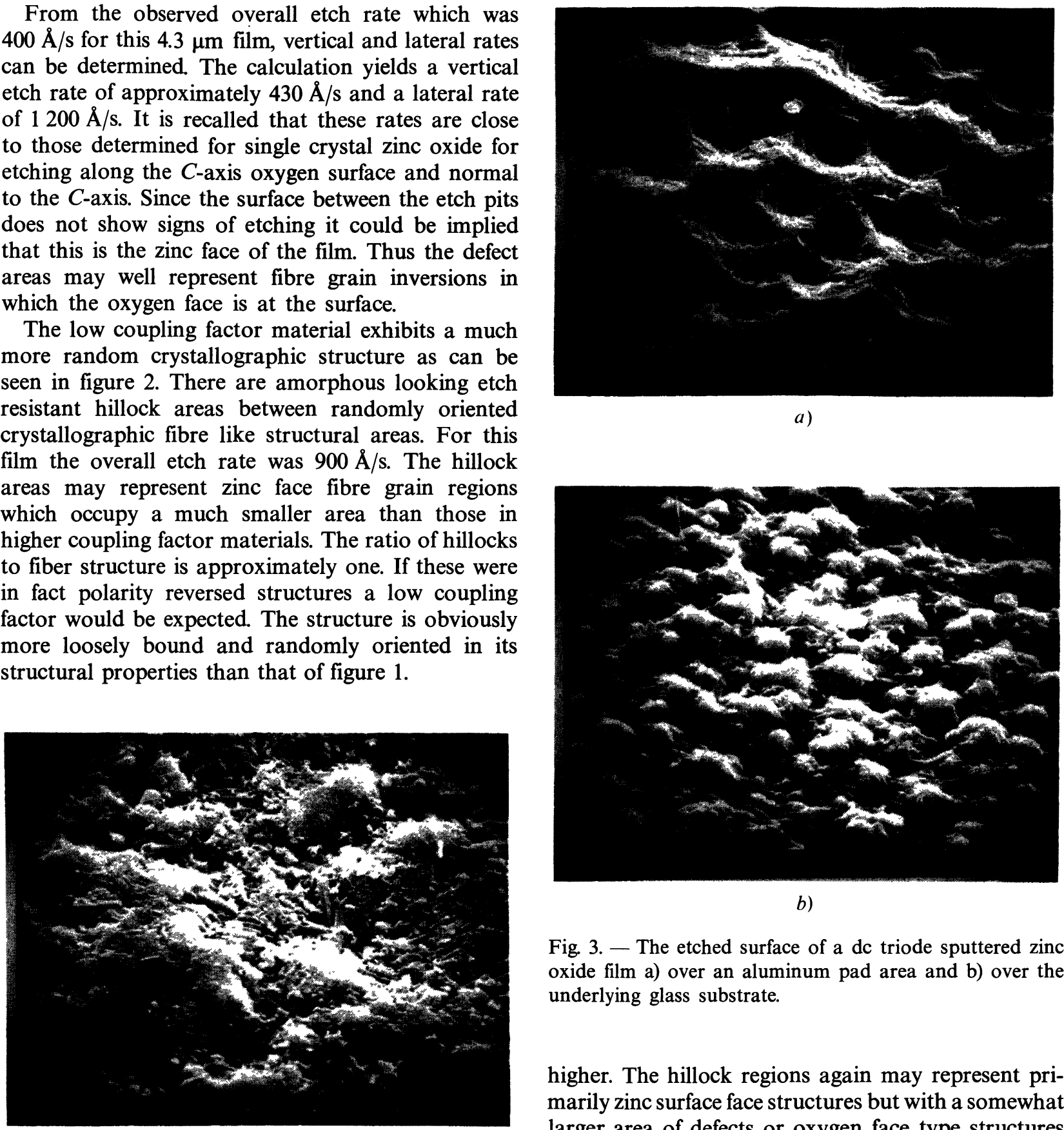

a)



b)

Fig. 3. - The etched surface of a dc triode sputtered zinc oxide film a) over an aluminum pad area and b) over the underlying glass substrate.

Fig. 2. - The etched surface of a low coupling factor dc triode sputtered zinc oxide film.

The influence of the presence of a metal electrode on film structure is shown in figure 3 where the partially etched film surface is examined on the aluminum pad area and its adjacent glass surface. An examination of these SEM photographs shows that the aluminum bond pad region (Fig. 3a) has the tighter bound conical etch pit structure while the glass substrate area (Fig. 3b) has a looser bound hillock type structure. The zinc oxide over the aluminum pad region had a lower etch rate than over the glass by a factor of two. The density of etch pits averaged 0.1 per micron squared over the aluminum and the hillock density was a factor of 1.5 marily zinc surface face structures but with a somewhat larger area of defects or oxygen face type structures surrounding them. The source of the defect areas is not known. Examination of the central area of a pit after etching through to the underlying substrate often reveals a small residual region of more etch resistant material. This region apparently forms initially in the deposition process and the structural defect is propagated upward as the film grows. The structural and compositional nature of the residual region is unknown.

The SEM examination of partially etched films substantiated the concept of structure as an important determinant of the efficiency of SAW transducers. While it is not possible to accurately quantize this factor, for the case of the high efficiency films examined ( $80 \%$ of theoretical coupling factor), the defect density was less than 0.1 defects per mir ometer squared. 


\section{Discussion of results.}

The microstructure of the high coupling factor sputtered zinc oxide films used in this investigation developed features which were associated with single crystal material. The films had a dense highly oriented polycrystalline structure. Individual fibre grains were small with strong boundary interconnections. The surface topography was smooth indicating a uniform growth rate across the film.

A correspondence between the etch characteristics of these triode sputtered films and the parent $\mathrm{ZnO}$ crystal was also observed. The etching started at defect sites and spread laterally at a rate which was approximately three times that vertically through the site. The regions between the sites showed little or no erosion due to the etch process. The lateral etch rate value corresponded to the value observed for etching normal to the $C$-axis of a zinc oxide crystal. The vertical etch rate of the film along the $C$-axis was of the same magnitude as that at the oxygen face of the crystal. The structural model which evolves from this picture is one in which the zinc face dominates at the film surface, interdispersed with polarity reversed fibre grains having an oxygen face surface.

The type of etch structure described for the dc triode sputtered $\mathrm{ZnO}$ films is observed with high rate, high temperature magnetron sputtered films but is not commonly seen in the lower rate, lower temperature diode sputtered films. Considering the observed fact that sputtered $\mathrm{ZnO}$ films develop with different dominant polarity features leads to the conclusion that the temperature at the growth surface may play an important role. The zinc surface of $\mathrm{ZnO}$ is known to grow the fastest and have a higher effective surface energy than the oxygen face. Thus higher temperature growth conditions which promote a zinc surface growth will tend to produce a higher structural quality film. This is borne out in the investigation described in this paper and can be inferred from the results reported elsewhere in the literature.

\section{References}

[1] Hickernell, F. S., 1980 Ultrasonics Symposium Proceedings (1980) 785.

[2] Wagers, R. S. and KINo, G. S., IEEE Trans. Sonics Ultrason., SU-21 (1974) 209.

[3] Dybwad, G. L., J. Appl. Phys. 42 (1971) 5192.

[4] Schoenwald, J. S., Keester, K. L. and Staples, E. J., 1979 Ultrasonics Symposium Proceedings (1979) 926.
[5] Mariano, A. N. and Hanneman, R. E., J. Appl. Phys. 34 (1963) 384.

[6] Bahr, A. J., Lee, R. E., Hickernell, F. S., WillingHAM, C. B. and REEDER, T. M., 1972 Ultrasonics Symposium Proceedings (1972) 202.

[7] Hickernell, F. S., Proc. IEEE 64 (1976) 631. 